\title{
Low-frequency Vibrations of Polyamide-6 as a Function of Temperature and Thermal History Investigated by Terahertz Absorption Spectroscopy
}

Hal Suzuki, ${ }^{*}$ Shinya Ishii, Chiko Otani, and Hiromichi Hoshina

RIKEN, 519-1399 Aramaki-Aoba, Aoba-ku, Sendai, Miyagi 980-0845, Japan

\section{Corresponding Author}

*Corresponding author. Phone: +81-22-228-2124. Fax: +81-22-228-2128.

E-mail address: h_suzuki@riken.jp (Hal Suzuki). 
Abstract. The $\alpha$ and $\gamma$ crystals of polyamide- 6 were examined by terahertz absorption spectroscopy from -90 to $230^{\circ} \mathrm{C}$. For the $\alpha$ crystals, the absorption band at $6.5 \mathrm{THz}$, assigned as a lattice vibration perpendicular to the molecular chain, decreased in intensity with increasing temperature, ending near the Brill transition temperature $\left(T_{\text {Brill }} \approx 160{ }^{\circ} \mathrm{C}\right)$. The band at $8.7 \mathrm{THz}$, assigned as the skeletal vibration along the molecular chain, shifted to higher frequency with increasing temperature. The rate of shift changed at the glass transition temperature $\left(T_{\mathrm{g}} \approx 50{ }^{\circ} \mathrm{C}\right)$, indicating coupling of the molecular vibration in the crystal with freezing/relaxing phenomena in the surrounding amorphous phase. A significant annealing effect was observed. On heating polyamide- 6 films that had been annealed at a temperature $\left(T_{\text {ann }}\right) \geq 80^{\circ} \mathrm{C}$, an increase in spectral intensity above $9 \mathrm{THz}$ occurred at $\sim T_{\text {ann }}$, due to the melting of semi-crystals formed by recrystallization during annealing.

Keywords: terahertz absorption spectroscopy, polyamide-6, Brill transition, glass transition, thermal history 


\section{Introduction}

The physical properties of crystalline polymers are difficult to investigate in detail because of their inhomogeneous, non-equilibrium natures. To achieve a complete understanding of these materials, comprehensive studies that consider the crystal structure, crystallinity, crystal size, and their dependence on temperature and thermal history are needed. Recently several works have been published, discussing the relation between structure and dynamics in crystalline polymers by combining techniques of neutron and X-ray scattering, and dielectric spectroscopy. ${ }^{1-3}$ The interplay between inter- and intra-molecular dynamics in amorphous polymer has also been revealed by dielectric spectroscopy, nuclear magnetic resonance, infrared spectroscopy, and differential scanning calorimetry. ${ }^{4}$ In this work, we investigated the low-frequency vibrations of crystalline polyamide-6 (PA6) to elucidate the intermolecular vibrations and molecular conformations changing as functions of temperature and thermal history.

PA6, also known as nylon-6, is a crystalline polymer used in various industrial products. Consisting of repeating $\left[-\mathrm{NH}-\mathrm{CO}-\left(\mathrm{CH}_{2}\right)_{5}-\right]$ units, the polymer chains are connected intermolecularly by hydrogen bonds $(\mathrm{N}-\mathrm{H} \cdots \mathrm{O}=\mathrm{C})$. PA6 shows crystalline polymorphism, and two crystalline phases ( $\alpha$ and $\gamma$ ) are well known (Figure 1$).^{5-12}$ In the $\alpha$ crystals, neighboring extended chains are connected by hydrogen bonds to form a sheet 
structure. The distance between neighboring sheets is shorter than that between hydrogen-bonded chains, which results in an asymmetric lattice structure, $a \neq c$. The $\gamma$ crystals, on the other hand, consist of twisted molecular chains, and the lattice constants $a$ and $c$ are close in value. Thermodynamically, the $\alpha$ crystal is more stable than the $\gamma$ crystal. ${ }^{9}$ Upon rapid cooling from the melt, PA6 prefers to crystallize first into the metastable $\gamma$ crystal, which can then transform into the $\alpha$ crystal by annealing above 120 ${ }^{\circ} \mathrm{C} .{ }^{13}$ The $\alpha$ phase undergoes a structural transition, known as the Brill transition, at $T_{\text {Brill }}$ $\approx 160{ }^{\circ} \mathrm{C}$. As the temperature rises from room temperature, the values of the $a$ and $c$ lattice constants gradually converge, and coincide at $T_{\text {Brill. }}$ The higher temperature phase is called the $\alpha^{\prime}$ crystal or pseudo-hexagonal (PH) phase, in which the lattice parameters $a$ and $c$ are nearly equal and librational motion of the molecular chain is possible. ${ }^{14-16}$

The crystallites are surrounded by an amorphous phase which has a glass transition at $\sim 54{ }^{\circ} \mathrm{C}\left(T_{\mathrm{g}}\right) .{ }^{6,10}$ The degree of crystallinity depends on the cooling rate from the melt, i.e., the amorphous portion increases with increasing cooling rate. Since the boundary between the crystalline and amorphous phases is not clear, various intermediate states have been proposed, such as imperfect crystals ${ }^{17}$ or rigid amorphous phases. ${ }^{18}$ Such intermediate states continuously reorganize to more ordered states with time and temperature. $^{13}$ 
$\mathrm{THz}$ absorption spectroscopy detects low-frequency vibrational modes between 0.1 and $10 \mathrm{THz}$. As techniques for the generation and detection of THz waves have been developed in recent years, ${ }^{19} \mathrm{THz}$ spectroscopy has recaptured interest in various research fields. ${ }^{20-23}$ For polymers, rich spectral features are observed in this frequency range, such as skeletal vibrations and the libration of side groups. ${ }^{24-32}$ As these motions are strongly coupled with intermolecular motions, assignment is usually not a straightforward task. In crystalline polymers, lattice phonon modes can also be detected, which depend sensitively on the crystal structure. Therefore, THz spectroscopy provides information not only about the local conformations in the polymer chains but also about the packing structures of the chains.

In this work, we measured the THz absorption spectra of PA6 in different condensed forms under various thermal conditions. By comparing those results with differential scanning calorimetry (DSC) and X-ray diffraction (XRD) measurements, the conformational changes due to temperature variations and thermal history were investigated in detail. 


\section{Experimental}

PA6 pellets $\left(M_{\mathrm{w}} \approx 10,000 ; \rho \approx 1.08 \mathrm{~g} \mathrm{~cm}^{-3}\right)$ were purchased from Sigma Aldrich and used without further purification. The pellets were first heated above the fusion temperature and then pressed into a film with a thickness of 100-200 $\mu \mathrm{m} . \alpha$ and $\gamma$ crystals were obtained by annealing the supercooled liquid at $190{ }^{\circ} \mathrm{C}(15 \mathrm{~h})$ and $100{ }^{\circ} \mathrm{C}(5 \mathrm{~h})$, respectively. Since crystallinity depends sensitively on thermal history, one piece of the sample film was divided into several pieces for analysis by $\mathrm{THz}$ spectrometry, XRD measurement, and DSC.

The THz spectra (1-11 THz) were obtained by Fourier-transform far-infrared (FT-FIR) spectroscopy with a frequency resolution of $0.06 \mathrm{THz}$. The measurements were conducted using a JASCO FARIS instrument equipped with a high-pressure mercury lamp, Mylar beam splitter, and a Si bolometer. The sample chamber was purged with dry nitrogen gas to reduce the absorption of water vapor. The film sample was placed on a highly resistive Si plate that was horizontally attached on a temperature-controlled heating stage (Linkam 19113L). A transmission-type optical geometry was adopted. The sample temperature was changed from -90 to $230{ }^{\circ} \mathrm{C}$, which was indirectly measured using a platinum resistor sensor attached on the heating stage. The temperature difference between the stage and the Si surface was calibrated in advance using a K-type 
thermocouple. Including the errors in calibration, the sample temperature was accurate to within $\pm 1{ }^{\circ} \mathrm{C}$.

The crystalline forms and their temperature dependence were confirmed by XRD measurements using a Rigaku SmartLab diffractometer equipped with a $\mathrm{Cu} \mathrm{K} \alpha \mathrm{X}$-ray generator $(\lambda=0.154056 \mathrm{~nm})$ operating at $40 \mathrm{kV}$ and $30 \mathrm{~mA}$, and a temperature controller (Anton Paar, DCS 350). The sample film was horizontally attached on the heating stage, and the measurements were performed between -90 and $250{ }^{\circ} \mathrm{C}$ in the reflection mode. The sample temperature was measured using a PT100 thermocouple, which was accurate to within $\pm 0.2^{\circ} \mathrm{C}$.

The thermal properties of the PA6 films were characterized using a differential scanning calorimeter (SII Exstar X-DSC7000) from -80 to $250^{\circ} \mathrm{C}$ at a heating rate of 10 ${ }^{\circ} \mathrm{C} \min ^{-1}$.

\section{Results}

\subsection{THz spectra of liquid and crystalline $\alpha$ and $\gamma$ phases}

The $\alpha$ and $\gamma$ crystals were obtained by annealing the supercooled liquid at $190{ }^{\circ} \mathrm{C}$ for 15 $\mathrm{h}$ and $100{ }^{\circ} \mathrm{C}$ for $5 \mathrm{~h}$, respectively. The film surface of the $\alpha$ crystal was slightly degraded due to the long annealing, which however little affected the THz spectrum. 
The effect of moisture absorption, on the other hand, significantly changed the spectrum, since PA6 is hygroscopic. ${ }^{33}$ Therefore the sample films were dried at $113{ }^{\circ} \mathrm{C}$ ( $\alpha$ crystal) and $95{ }^{\circ} \mathrm{C}$ ( $\gamma$ crystal $)$ for 10 min under nitrogen gas flow $\left(40 \mathrm{~L} \mathrm{~min}^{-1}\right)$ before the measurements. Figure 2 (a) shows the XRD patterns of the two crystalline phases at $0{ }^{\circ} \mathrm{C}$ together with that of the liquid phase at $230^{\circ} \mathrm{C}$. For the $\alpha$ crystal, two characteristic diffraction peaks are observed at $20^{\circ}$ and $23.5^{\circ}$. For the $\gamma$ crystal, one small peak is observed on a broad peak centered at $21^{\circ}$. For the liquid phase, a broad asymmetric peak centered at $18.5^{\circ}$ is observed, showing that the molecular chains still roughly retain a periodic structure because of the strong hydrogen bonding between them. Figure 2 (b) shows the THz spectra of the two crystalline phases at $1{ }^{\circ} \mathrm{C}$ and the liquid at $227^{\circ} \mathrm{C}$. The $\alpha$ crystal spectrum reveals two large bands at 3.2 and $8.7 \mathrm{THz}$, together with small bands at $2.0,5.8,6.5$, and $10.3 \mathrm{THz}$. The band at $8.7 \mathrm{THz}$ consists of two components. The spectrum for the $\gamma$ crystal shows two large, broad bands at 3.2 and $9.3 \mathrm{THz}$, where the latter consists of two components. The reduced number of bands in the $\gamma$ crystal may be because several optical phonon modes observed in the $\alpha$ crystal become degenerate because of its symmetric structure $(a \approx c)$. These results are consistent with those in previous work. ${ }^{5,34}$ The liquid phase spectrum exhibits two very broad bands centered at 2.5 and $9.2 \mathrm{THz}$, which may be intramolecular modes or the vibrations of hydrogen 
bonds. For the $\alpha$ crystal, polarized THz spectroscopy for stretched films was also conducted, where the bands at 2.0 and $8.7 \mathrm{THz}$ were assigned to the vibrational modes along the molecular chain, while those at $3.2,5.8,6.5$, and $10.3 \mathrm{THz}$ were perpendicular to the chain. ${ }^{35}$ Precise mode assignments by quantum mechanical calculations are presently ongoing. ${ }^{35}$

\subsection{Temperature Variation of THz Spectra}

Figure 3 (a) shows the temperature variation of the THz spectrum for the $\alpha$ crystal. The bands at 5.8, 6.5, and $8.7 \mathrm{THz}$ significantly decrease in intensity with increasing temperature. The broad band at around $3 \mathrm{THz}$ changes shape with temperature in a rather complicated manner. To better visualize the spectral change, first derivatives of absorption intensities were taken with respect to temperature. Figure 3 (b) shows the first derivatives plotted two-dimensionally against frequency and temperature. The red areas represent positive values, indicating that the spectral intensity increases with temperature, and the blue ones indicate negative values, i.e., the intensity decreases with increasing temperature. The plot shows that the absorption intensities at $3-4 \mathrm{THz}, 6-7 \mathrm{THz}$, and 8.5 $-9 \mathrm{THz}$ continuously decrease as the temperature rises, whereas the intensities at $1-3$

$\mathrm{THz}$ and $9.5-11 \mathrm{THz}$ start increasing above $110^{\circ} \mathrm{C}$. The decrease in intensity at $3-4 \mathrm{THz}$ 
corresponds to the vanishing of the broad band, which takes place only at the higher-frequency side of the band. This indicates that the broad band consists of at least two components, and the band at higher frequency is temperature-dependent. The decrease in intensity at $6-7 \mathrm{THz}$ corresponds to the vanishing of the bands at 5.8 and 6.5 THz. The change continues up to $160{ }^{\circ} \mathrm{C}$, which is close to the Brill transition temperature. The decrease in intensity at $8.5-9 \mathrm{THz}$ is accompanied by an increasing trend at 9-9.5 THz, indicating that the band shifts to higher frequency with temperature. The increases in intensity at $1-3 \mathrm{THz}$ and $9.5-11 \mathrm{THz}$ seem to have a common origin, since both start at the same temperature, $110^{\circ} \mathrm{C}$, where the sample film was annealed $\left(T_{\mathrm{ann}} \approx 113{ }^{\circ} \mathrm{C}\right.$ ) to remove water before measurement. Thus, we suggest that the thermal history appears in the $\mathrm{THz}$ spectrum.

For the $\gamma$ crystal, the $\mathrm{THz}$ spectrum is less dependent on temperature in comparison (Figure 4). The broad peak at 3-4 THz decreases with increasing temperature, as do the intensities of the peaks at 8.5 and $9.5 \mathrm{THz}$. These declines finish near $130{ }^{\circ} \mathrm{C}$; thereafter, the absorption intensity at 5-9 THz increases with increasing temperature. The significant change near $130{ }^{\circ} \mathrm{C}$ may be due to the transformation of the $\gamma$ to the $\alpha$ crystalline phase. The spectral intensity above $10 \mathrm{THz}$ starts increasing at $\sim 100{ }^{\circ} \mathrm{C}$, similarly to the $\alpha$ crystal. This onset temperature $\left(\sim 100{ }^{\circ} \mathrm{C}\right)$ is close to the annealing 
temperature $\left(T_{\mathrm{ann}} \approx 95^{\circ} \mathrm{C}\right)$, indicating that the spectral change above $10 \mathrm{THz}$ is related to the annealing effect.

\section{Discussion}

\subsection{Brill and glass transitions}

Temperature variations in low frequency vibrations can be related to conformational changes. Figure 5 (a) shows the spectral changes of the $\alpha$ crystal between 5 and $7.5 \mathrm{THz}$. These bands are characteristic to the $\alpha$ crystal and correspond to vibrational modes perpendicular to the molecular chain. The significant decrease in band intensity with increasing temperature indicates that the observed mode is a phonon-like vibration rather than an intramolecular vibration. Both bands at 5.8 and $6.5 \mathrm{THz}$ shift slightly to lower frequency with increasing temperature, suggesting that the inter-chain distances are also changed. These results are consistent with the XRD measurements (Figure 6 (a), (b)), which demonstrate that the distance between the chains in the hydrogen-bonded sheet and that between the sheets are reduced as the temperature rises. Figure 5 (b) shows the maximum intensity for the spectral peak at $6.5 \mathrm{THz}$ plotted against temperature. The intensity decreases at a constant rate from -100 to $50{ }^{\circ} \mathrm{C}$, accelerates above $50{ }^{\circ} \mathrm{C}$, and stops at $160{ }^{\circ} \mathrm{C}$. These two inflection points correspond to $T_{\mathrm{g}} \approx 54{ }^{\circ} \mathrm{C}$ and $T_{\text {Brill }} \approx 160{ }^{\circ} \mathrm{C}$. 
The anomaly at $T_{\text {Brill }}$ is reasonable, since the $d$-spacing changes also end at this temperature (Figure $6(\mathrm{~b})$ ). The change at $T_{\mathrm{g}}$ is rather interesting, because the band is characteristic to the $\alpha$ crystal although the glass transition takes place in the surrounding amorphous region. Thus, relaxation of the amorphous polymer influences the structural change in the neighboring $\alpha$ crystal. The temperature variations in the $d$-spacings (Figure 6 (b)) also show inflection points at $T_{\mathrm{g}}$, supporting the THz spectroscopy results.

The THz spectrum from 8 to $10 \mathrm{THz}$ was successfully fitted using two Voigt functions (Figure 7 (a)) from -90 to $150{ }^{\circ} \mathrm{C}$; the center frequencies are plotted against temperature in Figure 7 (b). Voigt functions were used because inhomogeneous broadening of band width due to the fluctuation of molecular arrangement was expected. Here, the band at lower frequency is designated "Band 1" and the other, "Band 2." The frequency of Band 1 shifts from 8.75 to $8.96 \mathrm{THz}$ with increasing temperature, accelerating at $\sim 50{ }^{\circ} \mathrm{C}$ and decelerating at $\sim 170{ }^{\circ} \mathrm{C}$ (Figure 7 (b)). As with the band at $6.5 \mathrm{THz}$, the former temperature corresponds to $T_{\mathrm{g}}\left(\sim 54^{\circ} \mathrm{C}\right)$ and the latter corresponds to $T_{\text {Brill }}\left(\sim 160^{\circ} \mathrm{C}\right)$. Since Band 1 reflects the vibrational mode parallel to the molecular chain, it is clear that not only the inter-chain distance but also the intra-chain structure changes with temperature, stopping at $T_{\text {Brill. }}$ The anomaly at $T_{\mathrm{g}}$ suggests that the softening of the amorphous phase at this temperature also influences the skeletal vibrations along the 
molecular chain in the $\alpha$ crystal. Significant coupling between amorphous and crystalline domains has also been observed in high-density polyethylene. ${ }^{36}$ The relaxation in the amorphous phase at $T_{\mathrm{g}}$ may reduce the external pressure acting on the crystalline phases, and change the crystal structure.

The peak-top frequency of Band 2, on the other hand, does not significantly depend on temperature (Figure 7 (b)). Considering that a similar broad band is observed for the liquid phase at 9.2 THz (Figure 2 (b)), Band 2 may be due to skeletal vibrations in the amorphous region. It is interesting that no anomaly is observed at $T_{\mathrm{g}}$, suggesting that structural relaxation in the amorphous phase is uncoupled from this mode. This may be because the skeletal vibrations in the amorphous phase are only slightly affected by the external pressure due to the rearrangements of the disordered molecular chains.

\subsection{Thermal History}

The temperature variation of the spectral intensity at $9-11 \mathrm{THz}$ as well as the intensity of Band 1 suggests that the annealing process $\left(T_{\mathrm{ann}} \approx 113^{\circ} \mathrm{C}\right.$ for $\left.10 \mathrm{~min}\right)$ may influence the THz spectrum. To confirm this, four PA6 films ( $\alpha$ crystal) were prepared at different annealing temperatures $\left(76^{\circ} \mathrm{C}(20 \mathrm{~min}), 113{ }^{\circ} \mathrm{C}(10 \mathrm{~min}), 150{ }^{\circ} \mathrm{C}(10 \mathrm{~min})\right.$, and $\left.177^{\circ} \mathrm{C}(10 \mathrm{~min})\right)$ and their $\mathrm{THz}$ spectra were measured. Figure 8 presents 
two-dimensional plots of the first derivatives between 8 and $11 \mathrm{THz}$. The onset temperature of the spectral intensity change depends on the annealing temperature.

Similar annealing effects are also observed in the DSC traces (Figure 9), in which small endothermic peaks can be detected at $T_{\text {ann }}$. These results suggest that a small part of the crystal melts at the annealing temperature. The increase in the THz absorption intensity is explained that an increase in the liquid-like disordered conformation results in a growth of broad peak at $7-11 \mathrm{THz}$ (as in Figure $2(\mathrm{~b})$ ). It is indicated that a metastable crystal is generated during the annealing, ${ }^{37,38}$ which melts at $T_{\text {ann }}$ during the subsequent heating. Since no characteristic band for this metastable phase has been observed in $\mathrm{THz}$ spectrum, the structure seems similar to that of the $\alpha$ crystal or pseudo hexagonal phase.

\section{Conclusions}

THz absorption spectra were measured for the $\alpha$ and $\gamma$ crystalline forms of PA6 from -90 to $230{ }^{\circ} \mathrm{C}$ in the frequency range from 1 to $11 \mathrm{THz}$. The THz spectra of the $\alpha$ crystal, $\gamma$ crystal, and liquid phases were shown to be different, and good correspondence to the XRD results was confirmed. The absorption band of the $\alpha$ crystal at $6.5 \mathrm{THz}$, which was assigned as a mode perpendicular to the molecular chain, was found to decrease in 
intensity with increasing temperature, indicating that the molecular chain packing in the $\alpha$ crystals continuously loosens with temperature, up to $T_{\text {Brill. }}$ The band at $8.7 \mathrm{THz}$, corresponding to the vibration along the molecular chains in the $\alpha$ crystal, was found to shift in frequency with increasing temperature; the rate of shift increased at the glass transition point of the surrounding amorphous material. A correlation was confirmed between the skeletal vibration along the molecular chain in the $\alpha$ crystal and the slowly relaxing molecular motion in the amorphous phase. The partial melting of crystals was observed as an increase in the spectral intensity above $9 \mathrm{THz}$, which became significant at the annealing temperature. This was interpreted as due to the generation of semi-crystals with different melting temperatures as a result of varying the maximum annealing temperature.

\section{ACKNOWLEDGEMENTS.}

This work was supported by a Grant-in-Aid for Young Scientists (B) No. 25871138 from the Japan Society for the Promotion of Science (JSPS), and an Industry-Academia Collaborative R\&D grant from the Japan Science and Technology Agency (JST). XRD measurements of the PA6 films were conducted at the Materials Characterization Support 
Unit, RIKEN Center for Emergent Matter Science (CEMS), under the administration of Dr. Daisuke Hashizume. 


\section{References}

1. A. Sanz, A. Nogales, T. A. Ezquerra, M. Soccio, A. Munari and N. Lotti, Macromolecules 43 (2), 671-679 (2010).

2. M. Laurati, P. Sotta, D. R. Long, L. A. Fillot, A. Arbe, A. Alegria, J. P. Embs, T. Unruh, G. J. Schneider and J. Colmenero, Macromolecules 45 (3), 1676-1687 (2012).

3. C.-Y. Chen, C.-F. Yang, U. S. Jeng and A.-C. Su, Macromolecules 47 (15), 5144-5151 (2014).

4. W. K. Kipnusu, W. Kossack, C. Iacob, P. Zeigermann, M. Jasiurkowska, J. R. Sangoro, R. Valiullin and F. Kremer, Soft Matter 9 (18), 4681-4686 (2013).

5. I. Matsubara and J. H. Magill, J. Polym. Sci., Part B: Polym. Phys. 11 (6), 1173-1187 (1973).

6. Y. P. Khanna, W. P. Kuhn and W. J. Sichina, Macromolecules 28 (8), 2644-2646 (1995).

7. P. Papanek, J. E. Fischer and N. S. Murthy, Macromolecules 35 (10), 4175-4182 (2002).

8. G. Rotter and H. Ishida, J. Polym. Sci., Part B: Polym. Phys. 30 (5), 489-495 (1992).

9. Y. Z. Zhang, Y. Zhang, S. W. Liu, A. P. Huang, Z. G. Chi, J. R. Xu and J. Economy, J. Appl. Polym. Sci. 120 (4), 1885-1891 (2011).

10. S. M. Aharoni, n-Nylons: Their Synthesis, Structure, and Properties. (Wiley, 1997).

11. D. R. Holmes, C. W. Bunn and D. J. Smith, J. Polym. Sci. 17 (83), 159-177 (1955).

12. N. S. Murthy, J. Polym. Sci., Part B: Polym. Phys. 44 (13), 1763-1782 (2006).

13. I. Kolesov and R. Androsch, Polymer 53 (21), 4770-4777 (2012).

14. C. Ramesh and E. B. Gowd, Macromolecules 34 (10), 3308-3313 (2001).

15. N. S. Murthy, S. A. Curran, S. M. Aharoni and H. Minor, Macromolecules 24 (11), 3215-3220 (1991).

16. N. Vasanthan, N. S. Murthy and R. G. Bray, Macromolecules 31 (23), 8433-8435 (1998).

17. M. Todoki and T. Kawaguchi, J. Polym. Sci. Polym. Phys. Ed. 15 (6), 1067-1075 (1977).

18. H. Chen and P. Cebe, J. Therm. Anal. Calorim. 89 (2), 417-425 (2007).

19. M. Tonouchi, Nat. Photonics 1 (2), 97-105 (2007).

20. H. Hoshina, T. Seta, T. Iwamoto, I. Hosako, C. Otani and Y. Kasai, J. Quant. Spectrosc. Radiat. Transf. 109 (12-13), 2303-2314 (2008).

21. K. Kawase, Y. Ogawa, Y. Watanabe and H. Inoue, Opt. Express 11 (20), 2549-2554 (2003).

22. K. Yamamoto, M. Yamaguchi, F. Miyamaru, M. Tani, M. Hangyo, T. Ikeda, A. Matsushita, K. Koide, M. Tatsuno and Y. Minami, Jpn. J. Appl. Phys. 243 (3B), L414-L417 (2004).

23. K. Fukunaga and M. Picollo, Appl. Phys. A-Mater. Sci. Process. 100 (3), 591-597 (2010).

24. G. N. Zhizhin, Optical Spectra and Lattice Dynamics of Molecular Crystals. (Elsevier Science, 1995). 
25. V. A. Bershtein and V. A. Ryzhov, in Polymer Analysis and Characterization (Springer Berlin Heidelberg, 1994), Vol. 114, pp. 43-121.

26. H. Hoshina, Y. Morisawa, H. Sato, A. Kamiya, I. Noda, Y. Ozaki and C. Otani, Appl. Phys. Lett. 96 (10) (2010).

27. H. Hoshina, S. Ishii, Y. Morisawa, H. Sato, I. Noda, Y. Ozaki and C. Otani, Appl. Phys. Lett. 100 (1) (2012).

28. H. Hoshina, Y. Morisawa, H. Sato, H. Minamide, I. Noda, Y. Ozaki and C. Otani, Phys. Chem. Chem. Phys. 13 (20), 9173-9179 (2011).

29. H. Hoshina, S. Ishii, S. Yamamoto, Y. Morisawa, H. Sato, T. Uchiyama, Y. Ozaki and C. Otani, IEEE Trans. THz Sci. Technol. 3 (3), 248-258 (2013).

30. N. Fuse, R. Sato, M. Mizuno, K. Fukunaga, K. Itoh and Y. Ohki, Jpn. J. Appl. Phys. 49 (10) (2010).

31. S. Wietzke, C. Jansen, T. Jung, M. Reuter, B. Baudrit, M. Bastian, S. Chatterjee and M. Koch, Opt. Express 17 (21), 19006-19014 (2009).

32. B. M. Fischer, S. Wietzke, M. Reuter, O. Peters, R. Gente, C. Jansen, N. Vieweg and M. Koch, IEEE Trans. THz Sci. Technol. 3 (3), 259-268 (2013).

33. K. Kawasaki and Y. Sekita, J. Polym. Sci. Part A 2 (5), 2437-2443 (1964).

34. H. Suzuki, S. Ishii, H. Sato, S. Yamamoto, Y. Morisawa, Y. Ozaki, T. Uchiyama, C. Otani and H. Hoshina, Chem. Phys. Lett. 575, 36-39 (2013).

35. E. Onishi, S. Yamamoto, H. Sato, D. Ishikawa, H. Hoshina, Y. Morisawa and Y. Ozaki, (to be published, 2014).

36. S. Wietzke, C. Jansen, M. Reuter, T. Jung, J. Hehl, D. Kraft, S. Chatterjee, A. Greiner and M. Koch, Appl. Phys. Lett. 97 (2), 022901 (2010).

37. G. R. Strobl, T. Engelke, H. Meier, G. Urban, H. G. Zachmann, R. Hosemann and V. Mathot, Colloid. Polym. Sci. 260 (4), 394-403 (1982).

38. Gert R. Strobl, The Physics of Polymers, Concepts for Understanding Their Structures and Behavior. (Springer, 2007). 


\section{Figure Captions}

Figure 1 Schematic representation of crystal structures for (a) $\alpha$ and (b) $\gamma$ crystals. $^{12}$

Figure 2 (a) XRD patterns of $\alpha$ and $\gamma$ crystals at $0{ }^{\circ} \mathrm{C}$, together with that of the liquid phase at $230{ }^{\circ} \mathrm{C}$. (b) $\mathrm{THz}$ spectrum of the two crystalline phases at $1{ }^{\circ} \mathrm{C}$ and the liquid at $227^{\circ} \mathrm{C}$.

Figure 3 (a) Temperature variation of the THz spectrum for the $\alpha$ crystal. (b) First derivatives of spectral intensity with respect to temperature plotted two-dimensionally against frequency and temperature for the $\alpha$ crystal; the red areas represent positive values of the first derivative, i.e., increases in spectral intensity with temperature, and the blue ones indicate negative values, i.e., decreases in intensity.

Figure 4 (a) Temperature variation of the THz spectrum for the $\gamma$ crystal, and (b) first derivatives of the spectral intensity with respect to temperature plotted two-dimensionally against frequency and temperature.

Figure 5 Temperature variation of (a) the THz spectrum for the $\alpha$ crystal between 5.0 and 7.5 THz, and (b) the peak-top intensity (height). 
Figure 6 (a) Temperature-dependent XRD patterns for $\alpha$ crystals of PA6. (b) Plot of the $d$-spacings corresponding to the two peaks of the 200 and $002 / 202$ reflections against temperature.

Figure 7 (a) $\mathrm{THz}$ spectrum of the $\alpha$ crystal at $1{ }^{\circ} \mathrm{C}$ in the frequency range from 8 to 10 $\mathrm{THz}$, and the results of fitting by two Voigt functions. (b) Temperature variation in band frequencies for the two fitted functions.

Figure 8 Two-dimensional plots of first derivative THz spectra for $\alpha$ crystals annealed at different temperatures: (a) $76{ }^{\circ} \mathrm{C}(20 \mathrm{~min})$, (b) $113{ }^{\circ} \mathrm{C}(10 \mathrm{~min})$, (c) $150{ }^{\circ} \mathrm{C}(10 \mathrm{~min})$, and (d) $177{ }^{\circ} \mathrm{C}(10 \mathrm{~min})$.

Figure 9 DSC traces of $\alpha$ crystals of PA6 annealed at (a) $80{ }^{\circ} \mathrm{C}(20 \mathrm{~min})$, (b) $120{ }^{\circ} \mathrm{C}(10$ min), (c) $160{ }^{\circ} \mathrm{C}(10 \mathrm{~min})$, and (d) $190{ }^{\circ} \mathrm{C}(10 \mathrm{~min})$; a small endothermic anomaly is observed at around $T_{\mathrm{ann}}$. 
(a) $\alpha$ crystal

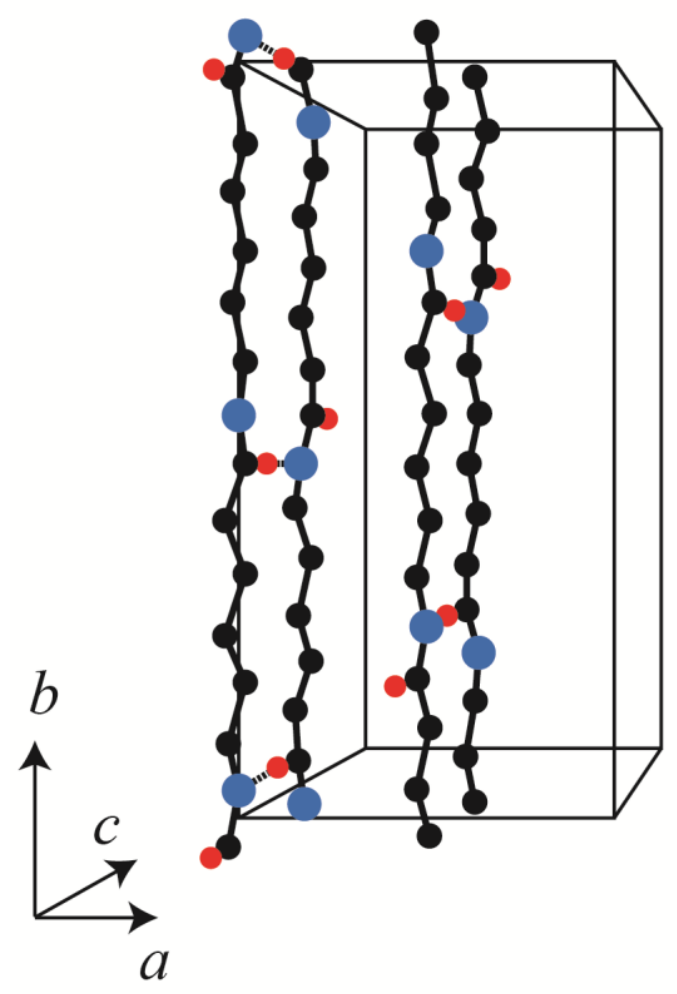

(b) $\gamma$ crystal

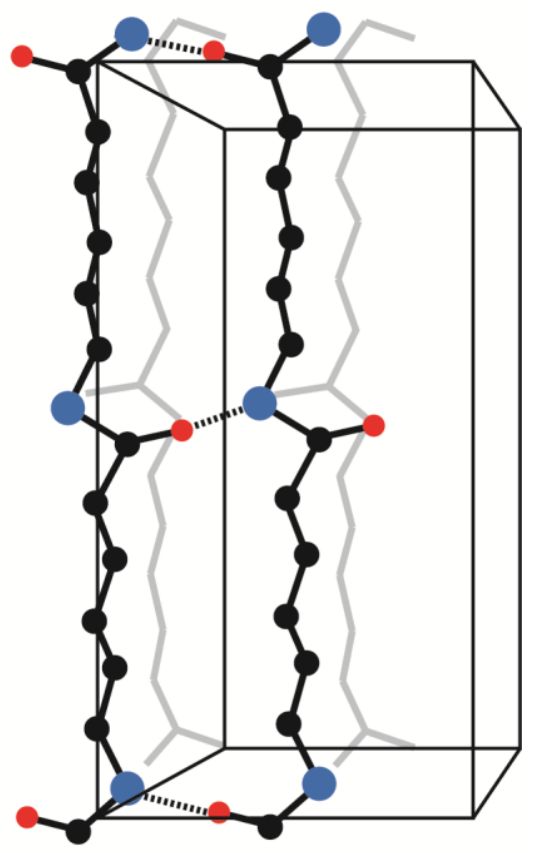

Figure 1 

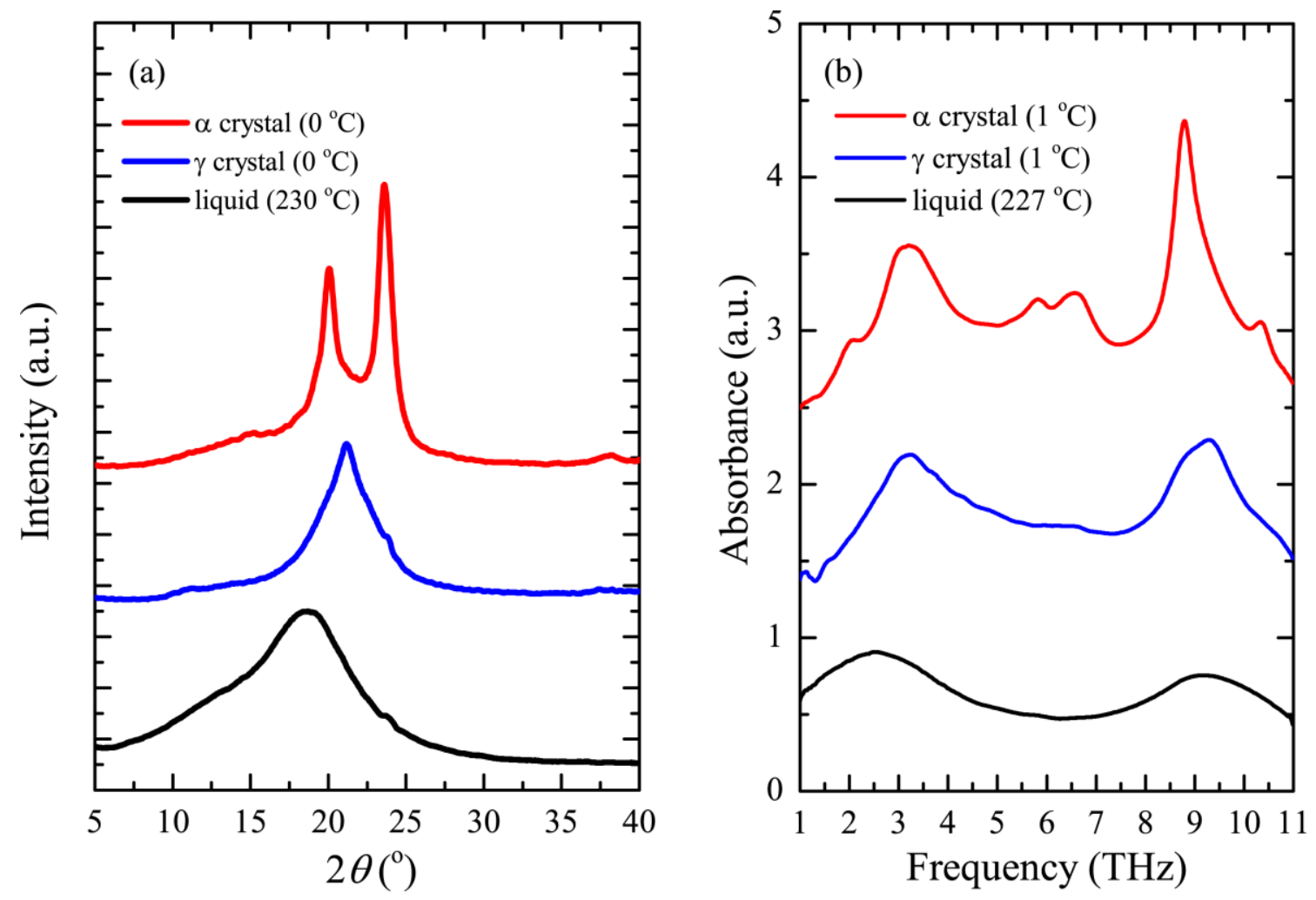

Figure 2 
Frequency $(\mathrm{THz})$

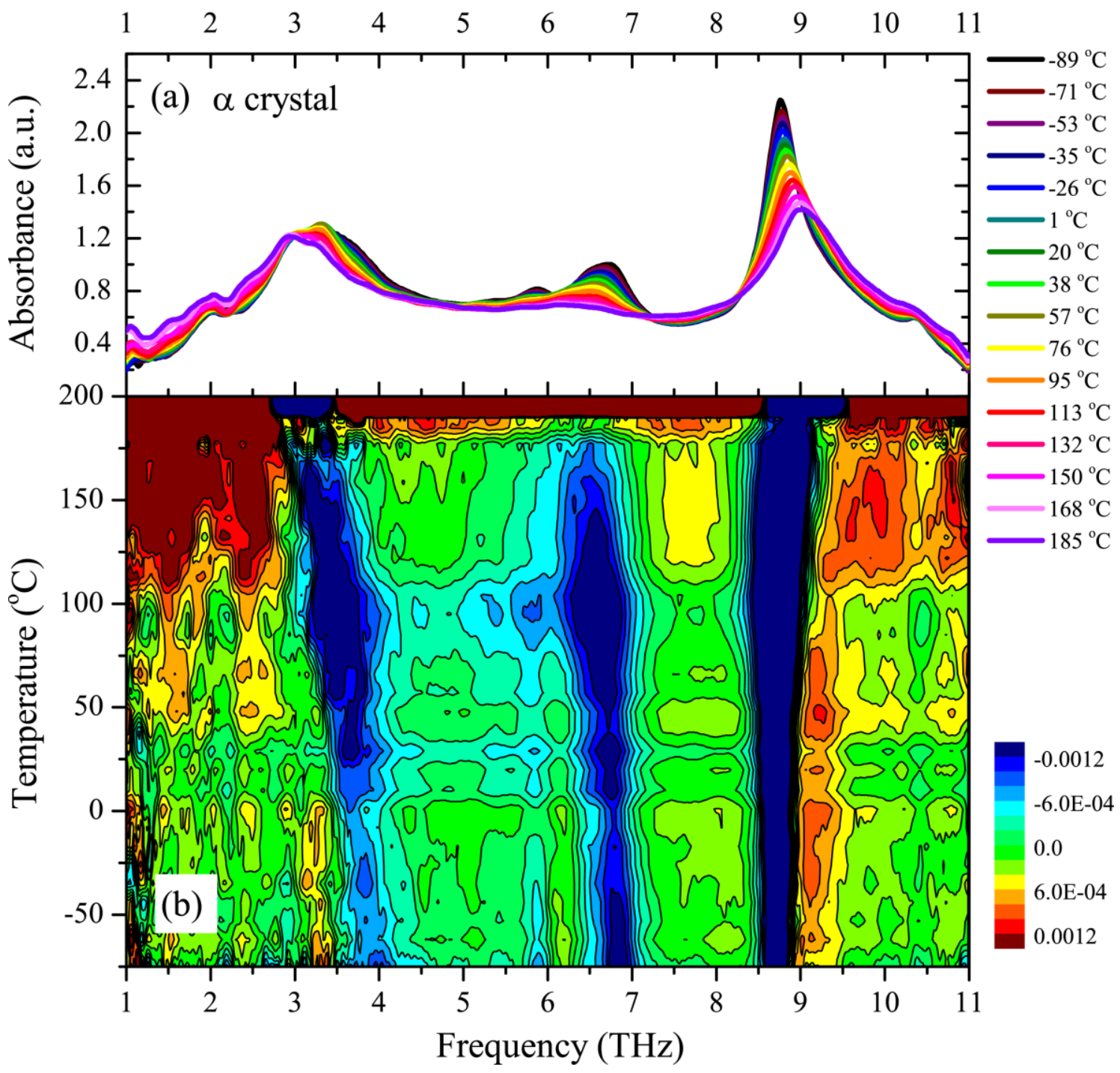

Figure 3 
Frequency $(\mathrm{THz})$

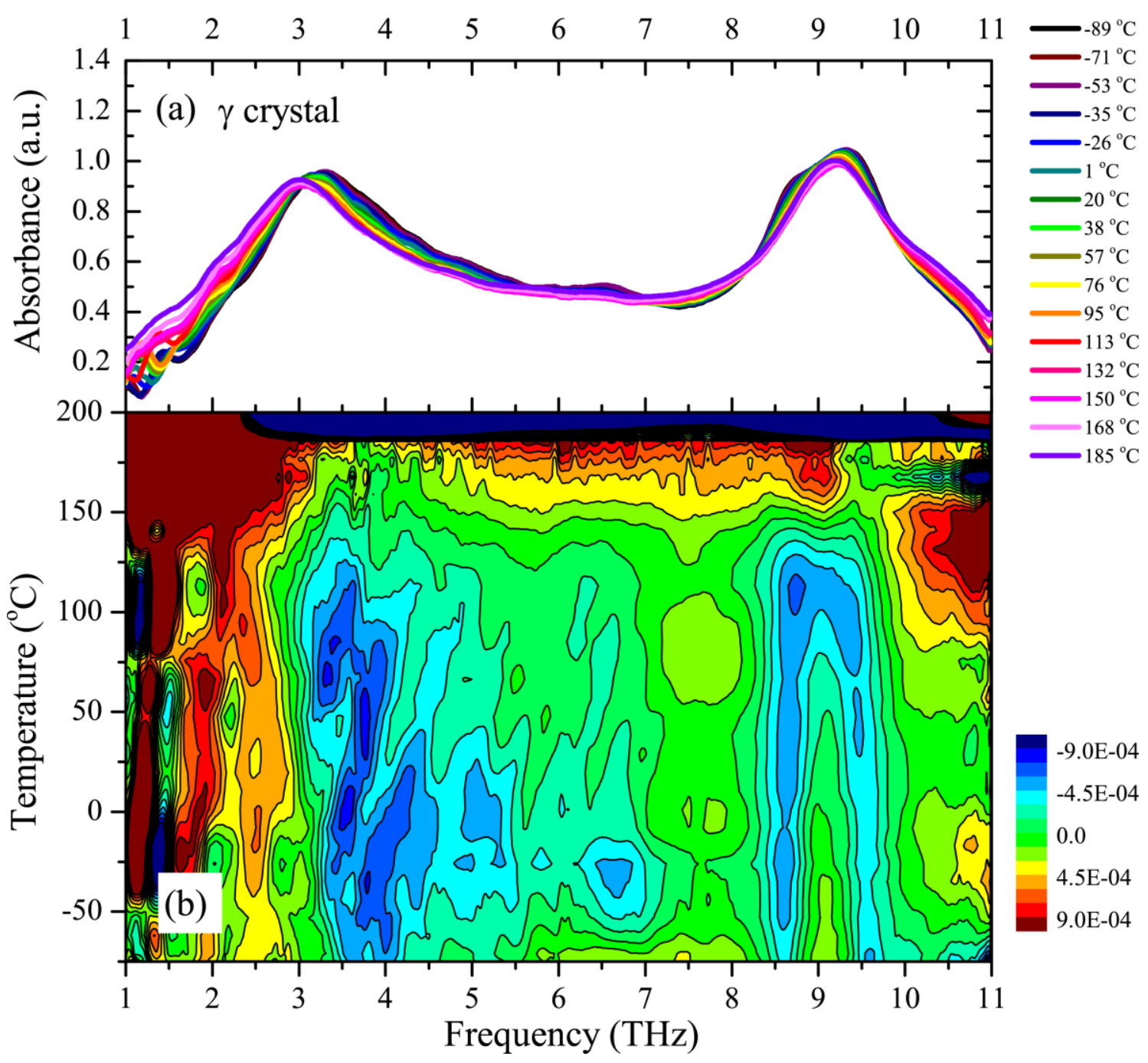

Figure 4 

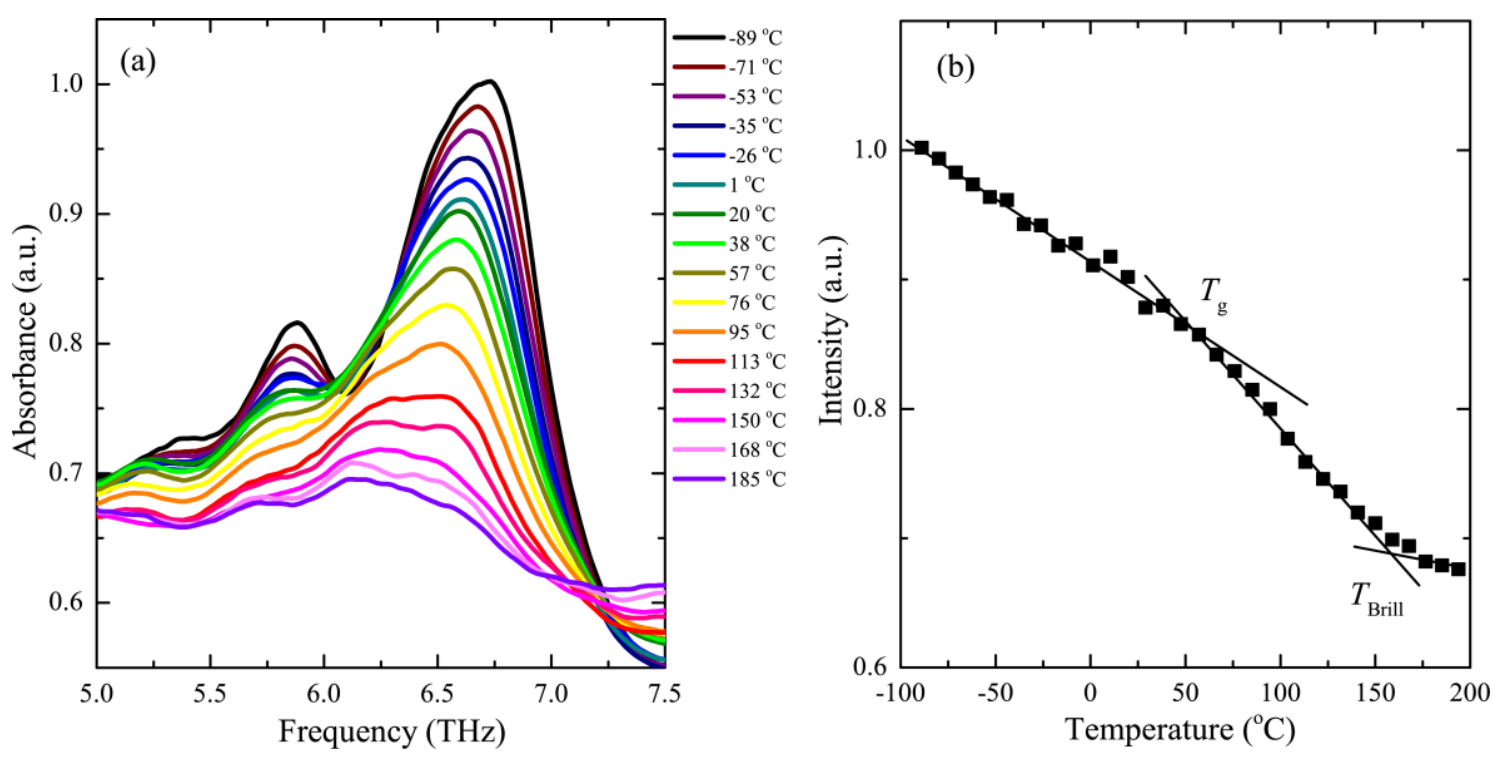

Figure 5 

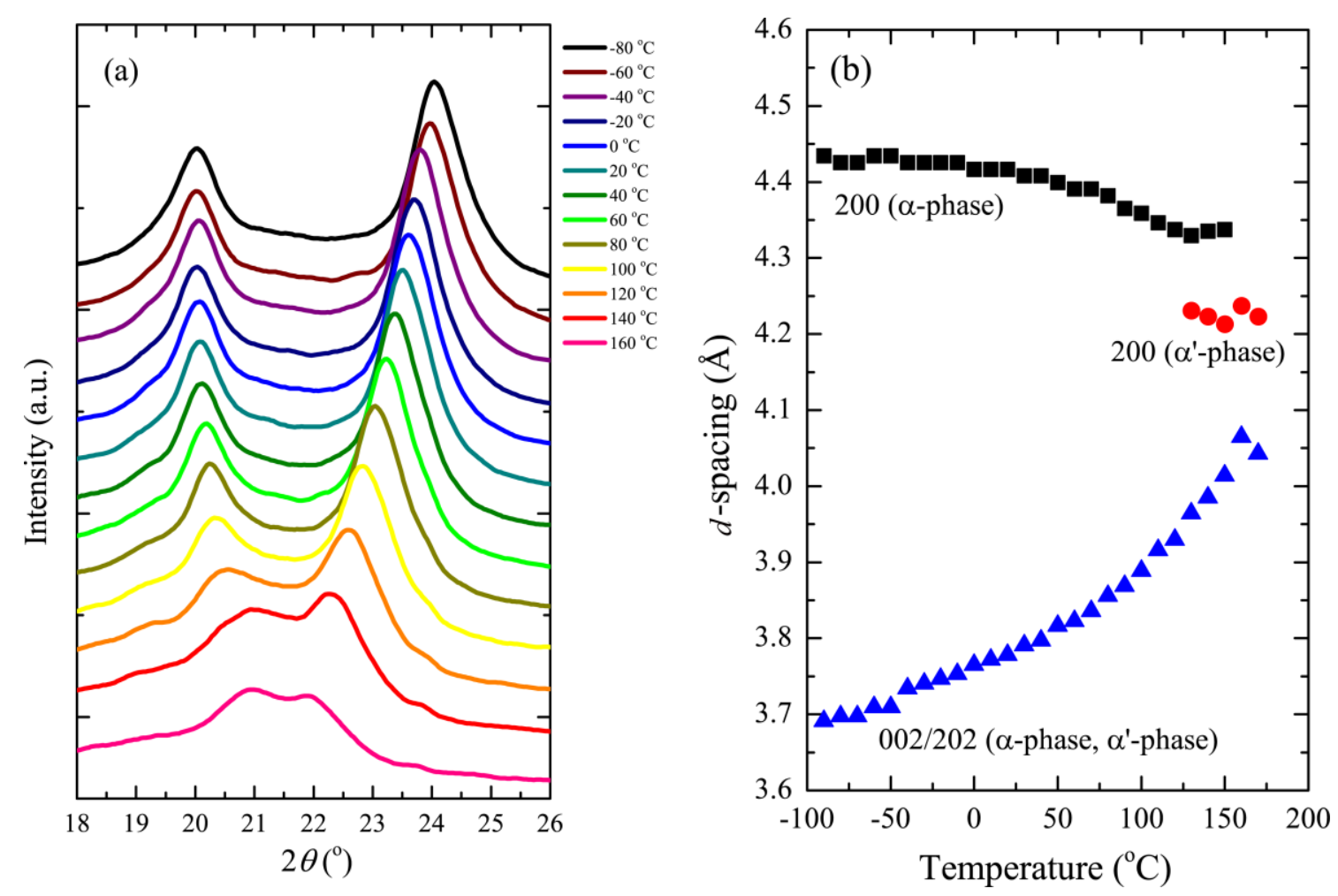

Figure 6 

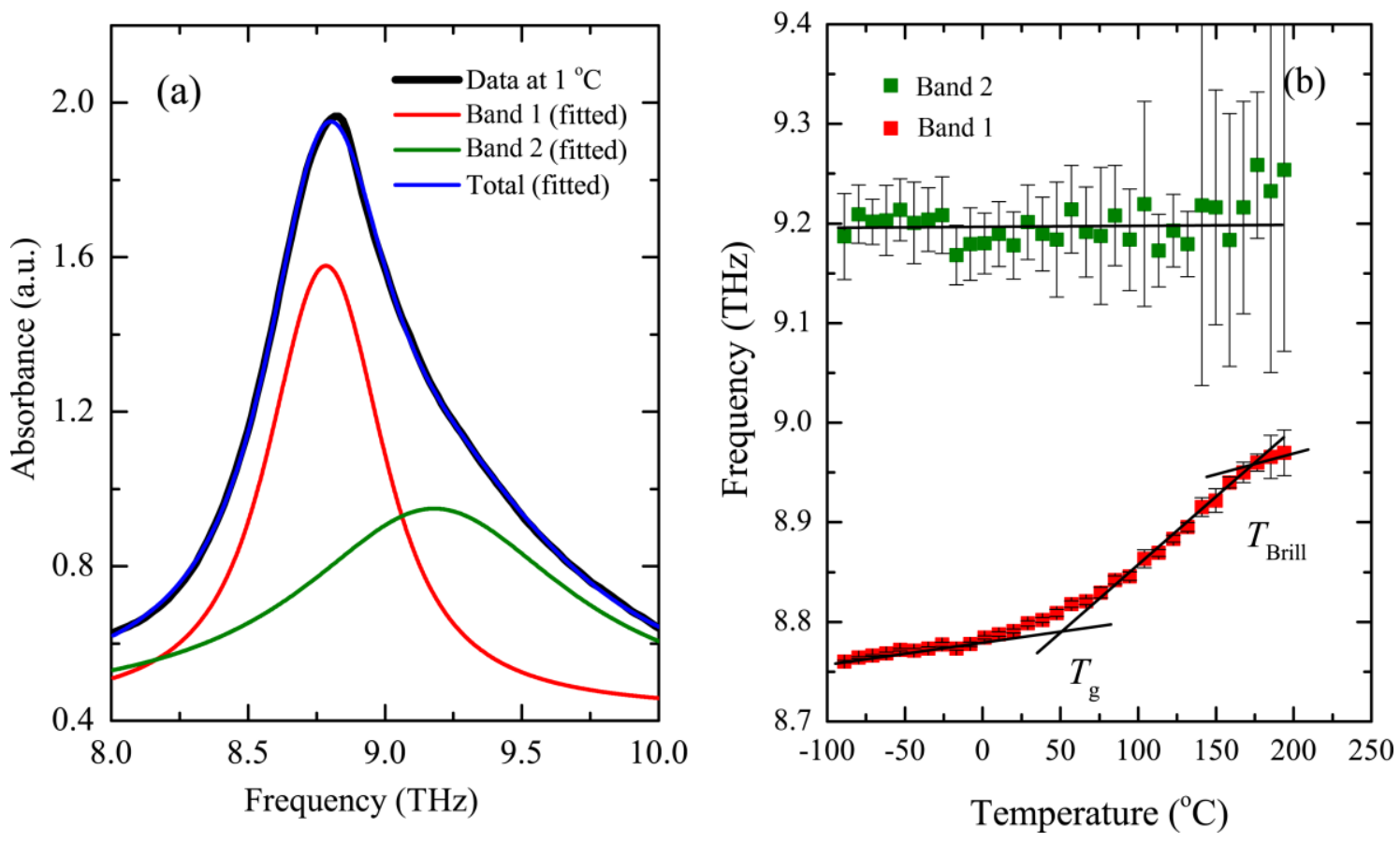

Figure 7 

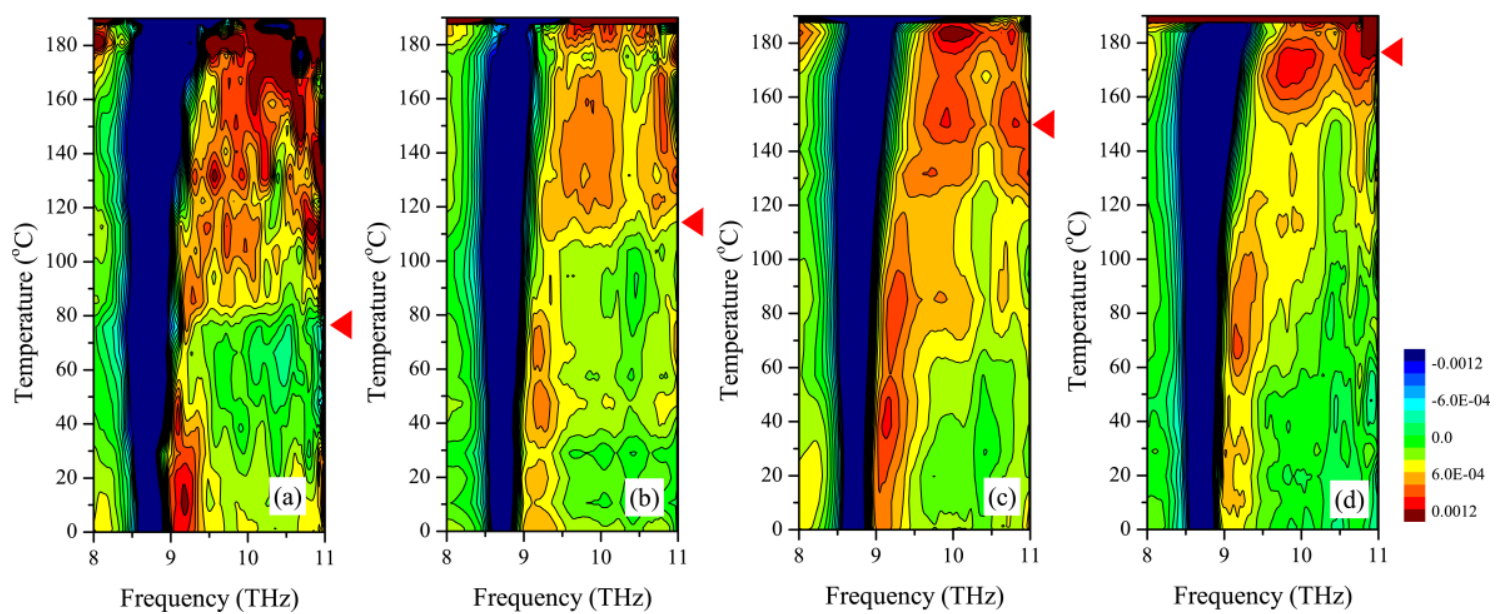

Figure 8 


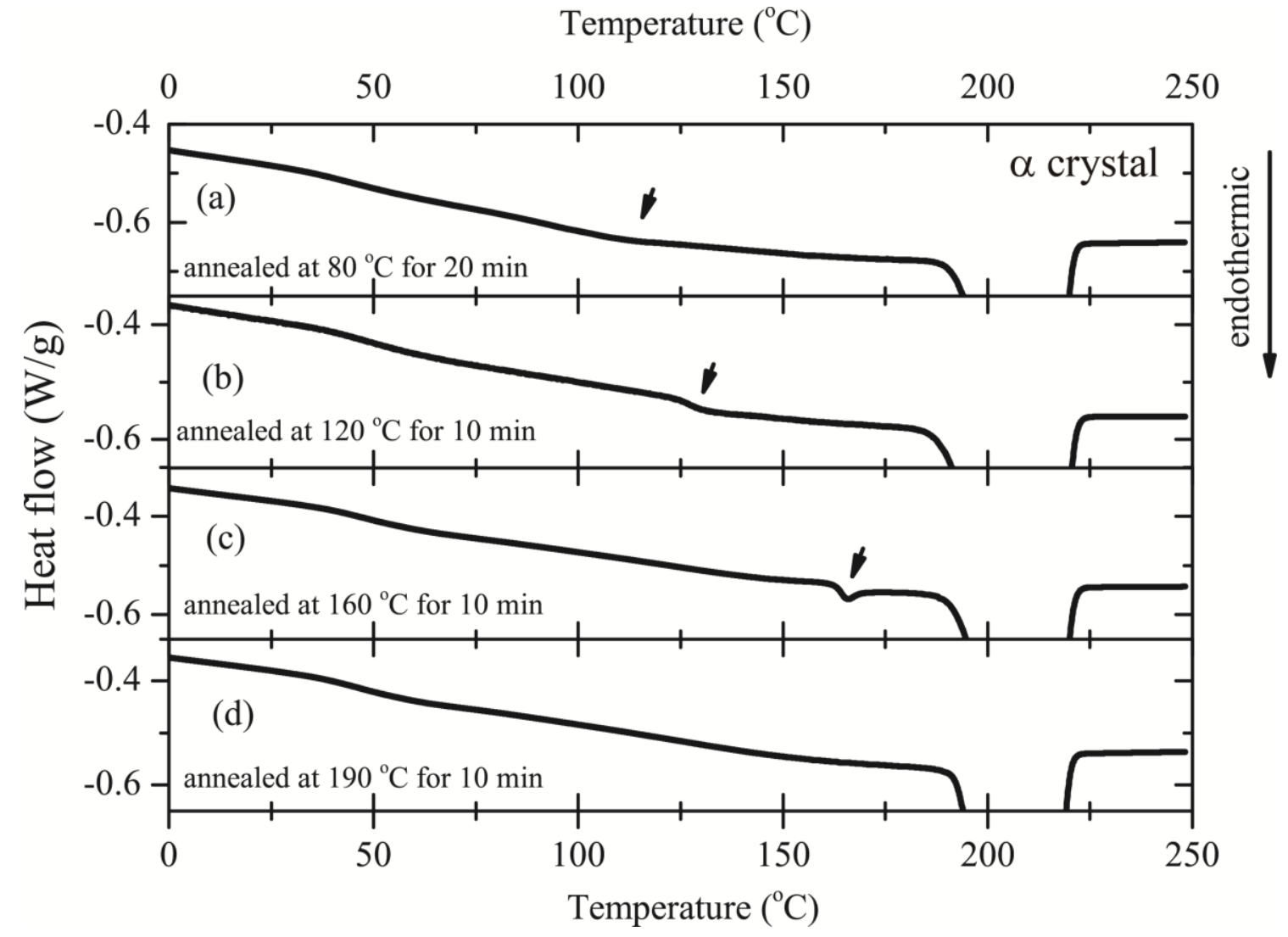

Figure 9 

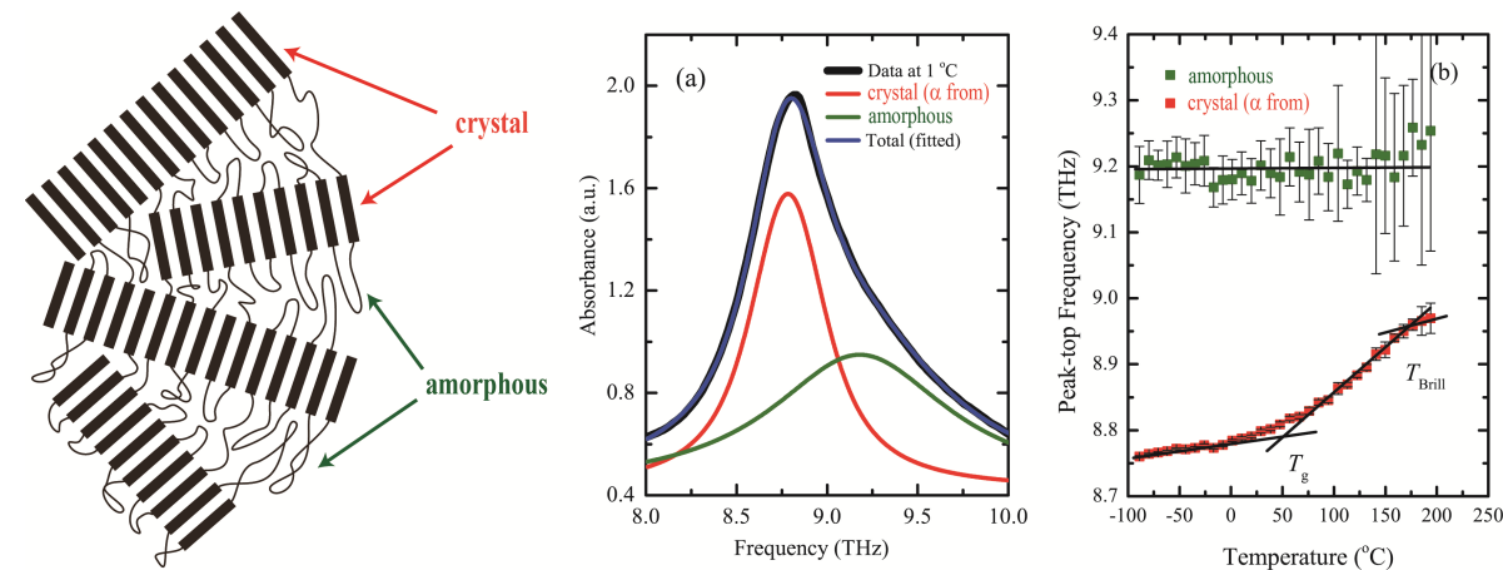

Graphical Abstract 